\title{
Assessment of Dental Caries and Intervention in the First Permanent Molars of Brazilian Children
}

Juliana Campos Chaves ${ }^{1}$, Tatiane Ramos dos $\operatorname{Santos}^{1} \mathbb{0}$, Mirian de Waele Souchois de Marsillac $1 \mathbb{0}$, Adilis Alexandria ${ }^{10}$, Tatiana Kelly da Silva Fidalgo ${ }^{10}$

${ }^{1}$ Department of Preventive and Community Dentistry, State University of Rio de Janeiro, Rio de Janeiro, RJ, Brazil.

Correspondence: Tatiana Kelly da Silva Fidalgo, Boulevard Vinte e Oito de Setembro, 157, Vila Isabel, Rio de Janeiro, RJ, Brazil. 20551-030. E-mail: tatianaksfidalgo@gmail.com

Academic Editor: Ana Maria Gondim Valença

Received: 18 January 2021 / Review: 26 May 2021 / Accepted: 14 June 2021

How to cite: Chaves JC, Santos TR, Marsillac MWS, Alexandria A, Fidalgo TKS. Assessment of dental caries and intervention in the first permanent molars of Brazilian children. Pesqui Bras Odontopediatria Clín Integr. 202 1; 21 :e0010. https://doi.org/10.1590/pboci.2021.152

\begin{abstract}
Objective: To evaluate the prevalence of caries stages and interventions on first permanent molars (FPM) in Brazilian children. Material and Methods: Data from FPM were extracted from dental records of children aged 5-14 years of age that attended the UERJ Pediatric Dentistry Clinic. Data include patient age, sex, biofilm index, presence of carious lesions in all stages, and the treatments. Data was analyzed using the SPSS ${ }^{\circledR} 20.0$ program. Results: A total of 158 dental records were analyzed, 587 registers were related to the caries stage and 601 related to the interventions; mean age of 8.26 ( \pm 1.4 years $)$ and $53.2 \%$ were girls. The prevalence of active/inactive white spot (AWS/IWS) varied from $14.3 \%$ to $21.6 \%$ in right upper and lower left FPM, respectively. Enamel/dentin lesions without pulp involvement were also more prevalent in the lower arch and ranged from $3.4 \%$ for the right upper to $11.5 \%$ for the lower right FPM. Cavities with pulp involvement or indicated extraction ranged from $0 \%$ to $1.4 \%$. Treatment included dental sealants, varying from 17.1 to $24.0 \%(\mathrm{n}=126)$ and restorations, varying from 1.3 to $11.8 \%(\mathrm{n}=38)$. The lower right were the most affected teeth. Conclusion: First permanent molars presented a higher prevalence of dental caries in early stages and the most prevalent treatment was related to the initial carious process, fluor therapy and sealants.
\end{abstract}

Keywords: Children; Dentition, Permanent; Dental Caries; Dental Care. 


\section{Introduction}

The first permanent molar erupts in the oral cavity at approximately six years of age, becoming more vulnerable and susceptible to the development of caries lesions in this period due to its early eruption and anatomical structure [1-5]. The first permanent molar is an extremely important dental element in the oral cavity. This teeth eruption impacts on third molar eruption contribute to the development of physiological occlusion and adequate masticatory function [6] and, frequently, parents of children did not attribute the correct relevance for this tooth [7]. Thus, several problems arise when it is lost, such as changing the position of the adjacent tooth and extruding the antagonist [8], and an expensive and multidisciplinary approach is required to avoid these undesirable sequels [9].

The difficulty of brushing these elements by those responsible or by the patient, the infra-occlusion that prevents the tooth from having contact with an antagonist for self-cleaning and the greater amount of fissures and fissures on the occlusal surface make the first permanent molar an element more susceptible to disease caries, which makes it a target of concern for dentists [10,11]. In addition, when the first permanent molar is erupting, it is less mineralized and undergoes post-eruptive maturation [12].

Tooth decay starts as a white spot lesion on tooth enamel. However, it could evolve and affect the pulp tissue, making treatment more complex and expensive. Furthermore, the element is still young and has incomplete rhizogenesis, leading to an unfavorable prognosis of endodontic therapy [13]. Thus, identifying the patient's risk and caries activity and the stage of the disease's evolution are important actions, especially in the initial phases, so that appropriate preventive and control measures are adopted to promote children's health [14]. Without treatment, the evolution of the disease can negatively impact the masticatory function, speech, smile, social interaction and quality of life of children and their families; in addition, dental treatment is expensive, which leads to a family economic impact [14,15]. Therefore, this study aimed to evaluate the prevalence of caries activity and treatments proposed on first permanent molars in children between 6 and 14 years of age.

\section{Material and Methods}

Ethical Clearance and Data Collection

The study was approved by the local research ethics committee (CEP / UERJ No. 1.675.731). A review of all dental records from patients attended from 2018 to 2019 in the Dental Clinic of the University of the State of Rio de Janeiro (UERJ) by last-year dentistry students and supervised by pediatric dentistry professors was carried out. The dental records of children from 5 to 14 years old with at least one erupted permanent first molar were included. Dental records with missing information or from children with systemic diseases were excluded.

Data include patient age, gender, biofilm index (O'Leary), absence or the presence of carious lesions and intervention. It was considered caries in all stages, independent of activity: initial caries lesion (active or inactive white spot - AWS/IWS), dentin cavity without pulp involvement, dentin cavity with pulp involvement, and dentin cavity with indicated extraction. For the treatment was considered: fluoride therapy, sealant, restoration, endodontic treatment or extraction. Biofilm index was classified according to the presence of visible biofilm (\%) in the tooth surface as excellent (less than 10\%), good (11-20\%), regular (21-30\%), and deficient (greater than $31 \%$ ), according to the amount of visible biofilm [16]. 
The data were tabulated, analyzed descriptively and statistically by SPSS ${ }^{\circledR}$ 20.0 program (SPSS Inc., Chicago, Ill., USA). The Chi-squared test $(\mathrm{p}<0.05)$ was applied to assess the possible association between gender and ages (grouped into 5-7, 8-9, and 10-12) with biofilm, oral hygiene, dental caries, and treatments.

\section{Results}

This study was carried out with dental records from a total of 188 children were recruited and 30 were excluded due to the incomplete data. From 158, 53.2\% girls and 46.8\% boys. The mean age was $8.26( \pm 1.4$ years). When analyzing the plaque index of these children, it was observed that $36.2 \%$ had an index classified as deficient, $16.2 \%$ as regular, $28.6 \%$ as good and $19.0 \%$ as excellent.

The dental caries status of the disease was analyzed, as well as previous treatments performed on first permanent molars. Table 1 shows that most of the first molars were healthy, with a prevalence of $75.13 \%$, ranging from $68.2 \%$ (lower left) to $81.0 \%$ (upper left). A higher prevalence of molars with an absence of caries was observed in the upper arch compared to the lower. There was a higher prevalence of initial dental caries stage, including active and inactive white spot (AWS/IWS) in the lower arch. The mean initial caries lesion (AWS/IWS) prevalence was $17.38 \%$ and varied from $14.2 \%$ for the right upper to $21.6 \%$ for the lower left first molar. Enamel and dentin lesions without pulp involvement were also more prevalent in the lower arch and ranged from $3.4 \%$ for the right upper to $11.5 \%$ for the lower right first molar. Carious lesions with pulp involvement or indicated extraction ranged from $0 \%$ to $1.4 \%$, being more prevalent in the lower right first molar. In general, it was observed that the first permanent lower molars had a greater prevalence of dental caries.

The fluoride therapy was preconized for $51.25 \%$ of the permanent first molars, ranging from $20.4 \%$ (lower right) to $23.3 \%$ (right upper). The mean of sealant prevalence was $20.97 \%$, varying from $17.1 \%$ for the lower right to $24.0 \%$ for the right upper first molar. The restoration mean prevalence was $6.32 \%$ and the most restored teeth were the lower right permanent molar (11.8\%). There is no association between gender and ages with biofilm, oral hygiene, dental caries, and treatments $(\mathrm{p}>0.05)$.

Table 1. Dental caries status of permanent first molars.

\begin{tabular}{lccccc}
\hline \multicolumn{1}{c}{ First Molar Condition } & $\begin{array}{c}\text { Right Upper } \\
\mathrm{N}(\%)\end{array}$ & $\begin{array}{c}\text { Left Upper } \\
\mathrm{N}(\%)\end{array}$ & $\begin{array}{c}\text { Lower Left } \\
\mathrm{N}(\%)\end{array}$ & $\begin{array}{c}\text { Lower Right } \\
\mathrm{N}(\%)\end{array}$ & $\begin{array}{c}\text { Total } \\
\mathrm{N}(\%)\end{array}$ \\
\hline Caries Stage $(\mathrm{n}=587)$ & $119(81.0)$ & $115(79.9)$ & $106(71.6)$ & $101(68.2)$ & $44.1(75.13)$ \\
$\quad$ No caries & $21(14.2)$ & $21(14.5)$ & $32(21.6)$ & $28(18.9)$ & $102(17.38)$ \\
MBA/MBI & $5(3.4)$ & $8(5.6)$ & $10(6.8)$ & $17(11.5)$ & $40(6.81)$ \\
Cavity without pulp involvement & $1(0.7)$ & $0(0.0)$ & $0(0.0)$ & $2(1.4)$ & $3(0.51)$ \\
Cavity with pulp involvement & $1(0.7)$ & $0(0.0)$ & $0(0.0)$ & $0(0.0)$ & $1(0.17)$ \\
$\quad$ Indicated extraction & & & & & \\
Dental Treatment (n=601) & $77(51.3)$ & $75(50.7)$ & $79(52.3)$ & $77(50.7)$ & $308(51.25)$ \\
No treatment & $35(23.3)$ & $32(21.6)$ & $31(20.5)$ & $31(20.4)$ & $129(21.46)$ \\
Fluoride therapy & $36(24.0)$ & $34(23.0)$ & $30(19.9)$ & $26(17.1)$ & $126(20.97)$ \\
Sealant & $2(1.3)$ & $7(4.7)$ & $11(7.3)$ & $18(11.8)$ & $38(6.32)$ \\
Restoration & $0(0.0)$ & $0(0.0)$ & $0(0.0)$ & $0(0.0)$ & $0(0.0)$ \\
Endodontic treatment & $0(0.0)$ & $0(0.0)$ & $0(0.0)$ & $0(0.0)$ & $0(0.0)$ \\
Extraction & & & & &
\end{tabular}

\section{Discussion}

This is a local study, and the patients that are attended at this local reference center presents low socio-economical level and higher prevalence of dental caries; therefore, the present findings contribute to 
determining health politics and the priories to this population. In the present study, considering the caries progression status, a higher prevalence of AWS and IWS was found compared to the other stages, with an overall prevalence of $17.38 \%$. The upper molars were the most affected teeth, with $18.9 \%$ in the right and $21.6 \%$ in the left

Mahboobi et al. [17] conducted a study in a 7- and 8-years old population and followed these children for two years, they found a prevalence of $75.7 \%$ of health first permanent molars in baseline and after two years, this prevalence decreased to $36.3 \%$. At follow-up examination, about a quarter of teeth had enamel caries and about $10-20 \%$ had a dentinal lesion. On the other hand, Gudipaneni et al. [18] also studied a population of children between 7 and 8 years old, and they found that most of first permanent molars presented initial caries lesion, enamel lesions, with a prevalence of $44.40 \%$ for upper right and $53.50 \%$ for left, and $61.30 \%$ for lower right and $64.90 \%$ for lower left [17].

In recent years, there has been a decline in caries in Brazilian schools due to improvements in access to primary health care services, the widespread use of fluoridated toothpaste, fluoridated water and collective preventive actions carried out in schools across the country, coordinated mainly by the public sector [19] However, despite the expansion of these preventive measurements, as demonstrated in this local population of the present study, there are still a large number of first permanent molars that have already initial caries lesion. Therefore, more individualized measurements are necessary to promote oral health.

The literature demonstrated that the first permanent molar begins its formation around the 6th week of intrauterine life. Its mineralization occurs at birth and the time required for the first permanent molars to erupt, varies from 5 to 32 months [20]. At approximately six years of age, this tooth erupts in the oral cavity, a period in which the element becomes more vulnerable and susceptible to the development and progression of caries lesions. This vulnerability is due to post-eruptive maturation, the element's position in the dental arch that prevents contact with the antagonist and generates a greater accumulation of biofilm, poor hygiene, and a diet rich in fermentable carbohydrates. The balance of indigenous oral microbiota can be disturbed by ingestion of fermentable carbohydrates and fasten the tooth demineralization [3,4]. Over time, calcium, phosphate and fluoride ions will be incorporated into the tooth enamel, which will provide greater resistance to the tooth structure [12].

The current study demonstrated that the prevalence of caries lesions with pulp involvement was low, ranging from $0 \%$ to $1.4 \%$. In this sense, it is important to highlight that the treatment of periapical pathologies in elements with an open apex represents a great challenge for endodontists [21-23]. Currently, despite the great diversity of biomaterials that stimulate apexification and the formation of an apical barrier of mineralized tissue, the roots remain thin, fragile and prone to possible fractures [22,23]. It is crucial for the early diagnostic of dental caries in the first permanent molar, therefore avoiding the progression of the lesion and, consequently, endodontic treatments on elements with incomplete rhizogenesis and early loss of elements, which negatively impacts the quality patient's life span. In this sense, besides the early diagnosis, the most important thing would be to act in prevention with instructions on hygiene and dietary change. The professional must be able to make the correct diagnosis so that he can intervene and prevent the progression of the disease. It is extremely important to have an early diagnosis, which allows conservative treatment instead of more invasive intervention. When performing the clinical examination of the patients' oral cavity, attention should be paid to the texture, brightness and coloring aspects of the initial carious lesions, characteristics that, when observed, determine the activity of the lesion. The use of isolated information such as dietary habits and 
oral hygiene has not shown sufficient sensitivity and specificity for a reliable definition of the risk of caries $[24,25]$.

The present study demonstrated that $52.4 \%$ were classified as deficient and regular plaque index. Moreira et al. [26] detected in $60.7 \%$ of the examined children, where the fully erupted tooth had a lower percentage of caries $(34 \%)$ while molars in infra-occlusion obtained almost $50 \%$ of the elements with the presence of caries. It can be seen that the children's oral hygiene was considered good, which corroborates the findings of the National Epidemiological Oral Health Survey (SB Brazil 2010) [27], where a significant reduction of caries prevalence was observed when compared to the National Epidemiological Oral Health Survey carried out in 2003. SB Brasil is a nationwide project to examine and evaluates epidemiologic data of oral health from Brazilian population.

Considering the proposed treatment for the first molars, the most prevalent treatment was fluoride therapy with $21.46 \%$. This finding is in agreement with the most prevalent dental caries progression status, active white spot. Quaglio et al. [28] demonstrated an association between the presence of white spot lesions in the occlusal surface of permanent first molar and the presence of white spot in other teeth in children aged from 5 to 13 years old. Therefore, when white spot was diagnosed and professional fluor therapy was proposed, the topic fluoride was applied in all teeth to avoid initial demineralization of other teeth. The second more predominant proposed treatment was restoration, with a prevalence of $20.9 \%$. It was found a small prevalence of caries lesions with an indication for extraction, ranging from $0 \%$ to $0.7 \%$. Silva et al. [29] demonstrated that early loss of first permanent molars in the lower dental arch was the most prevalent, corresponding to $47.73 \%$. The upper arch had a percentage of $34.09 \%$ and $18.18 \%$ in both arches. In the analysis of early tooth loss, the first right lower molar corresponded to the most affected element (11.27\%), which corroborates with the literature [28]. The first right lower molar (36) was in second place, with $9.80 \%$ of involvement. Therefore, the first right upper molar (16), with $8.33 \%$ and the left upper first molar (26), with $4.90 \%$. Studies also show that when there is past experience of dental caries, there is a significant increase in the recurrence of the disease $[18,28,30]$.

The first permanent molar is a tooth of great importance in the oral cavity. The first permanent molars are the most important teeth due to their key role in occlusion, considering the functional and developmental aspects. When this element is lost early, there are numerous complications as a consequence, such as the migration of the second molar to the mesial, the extrusion of the antagonist's tooth, the change in the positioning of the anterior teeth, spaces between teeth, changes in the midline, in the Spee curve and in the ATM $[8,30]$. In order to lessen these implications, orthodontic planning is necessary to establish the patient's normal occlusion and prevent further damage [6,31].

A limitation of the present study was the dental records were registered by multi dental students; however, all registries were confirmed by experienced pediatric dentistry professors. This study provided important information regarding a low-income local population, demonstrating that the initial caries stage was the most prevalent caries lesion. This information helps to plan more adequate health politics for this population, such as recommendations to reduce fermentable carbohydrates consumption, reinforce oral hygiene habits, and use regular concentration of fluoride toothpaste, besides an individualized approach is also recommended. More studies are necessary to deeper understand the main factors and risk factors that could influence the development of caries lesions in first molars.

\section{Conclusion}


The first right lower molar is the element most affected by caries. First permanent molars presented a higher prevalence of dental caries in early stages and the most prevalent treatment was related to the initial carious process, fluor therapy, and sealants. Therefore, it is necessary to promote oral health and carry out an accurate diagnosis of carious lesions to intervene early, which will avoid drastic consequences and guarantee a good prognosis of first permanent molars.

\section{Authors' Contributions}

\begin{tabular}{|c|c|c|}
\hline JCC & (D) https://orcid.org/0000-0003-0119-2086 & restigation, Writing - Original Draft and Writing - Review and Editing. \\
\hline TRS & https://orcid.org/0000-0001-7143-5050 & ysis, Writing - Original Draft and Writing - Review and Editing \\
\hline MWSM & $/ 0000-0002-4452-7336$ & ualization. \\
\hline $\mathrm{AA}$ & https://orcid.org/0000-0003-4774-1204 & $\begin{array}{l}\text { Conceptualization, Methodology, Formal Analysis, Writing - Review and Editing and } \\
\text { Visualization. }\end{array}$ \\
\hline TKSF & $/ 0000-0003-1340-9967$ & $\begin{array}{l}\text { Conceptualization, Methodology, Formal Analysis, Investigation, Data Curation, Writing - } \\
\text { Original Draft, Writing - Review and Editing, Supervision and Project Administration }\end{array}$ \\
\hline
\end{tabular}

\section{Financial Support}

None.

\section{Conflict of Interest}

The authors declare no conflicts of interest.

\section{Data Availability}

The data used to support the findings of this study can be made available upon request to the corresponding author.

\section{References}

[1] Sampaio-Maia B, Caldas IM, Pereira ML, Pérez-Mongiovi D, Araujo R. The oral microbiome in health and its implication in oral and systemic diseases. Adv Appl Microbiol 2016; 97:171-210. https://doi.org/10.1016/bs.aambs.2016.08.002

[2] Fontana M. The clinical, environmental, and behavioral factors that foster early childhood caries: evidence for caries risk assessment. Pediatr Dent 2015; 37(3):217-25.

[3] Grigalauskienė R, Slabšinskienè E, Vasiliauskienė I. Biological approach of dental caries management. Stomatologija $2015 ; 17(4): 107-12$.

[4] Colombo APV, Tanner ACR. The role of bacterial biofilms in dental caries and periodontal and peri-implant diseases: a historical perspective. J Dent Res 2019; 98(4):373-85. https://doi.org/10.1177/0022034519830686

[5] Al-Samadani KH, Ahmad MS. Prevalence of first permanent molar caries in and its relationship to the dental knowledge of 9-12-year olds from jeddah, kingdom of saudi arabia. ISRN Dent 2012; 2012:391068. https://doi.org/10.5402/2012/391068

[6] Sousa AS, Araújo FRL, Villela GSC, Normando D. Impact of early loss of lower first permanent molars on third molar development and position. Pesqui Bras Odontopediatria Clín Integr 2021; 21:e0072. https://doi.org/10.1590/pboci.2021.050

[7] Jetpurwala M, Sawant KR, Jain PS, Dedhia SP. Parental perception of the importance of the permanent first molar in their children. J Dent Child 2020; 87(1):26-30.

[8] American Academy of Pediatric Dentistry. Management of the developing dentition and occlusion in pediatric dentistry. Pediatr Dent 2018; 40(6):352-65.

[9] Sabri R. Multidisciplinary management of permanent first molar extractions. Am J Orthod Dentofacial Orthop 202 1; 159(5):682-92. https://doi.org/10.1016/j.ajodo.2020.09.024

[10] Bassir L, Khanehmasjedi M. Survey on the condition of first permanent molars in 15-year-old students in Ahwaz, Iran in 2005. J Dent Res Dent Clin Dent Prospects 2008; 2(2):58-62. https://doi.org/10.5681/joddd.2008.012

[11] Heydari A, Shahrabi M, Shafizadeh M, Anaraki E, Aref M. Parental knowledge and awareness of the first permanent molar. Int J Clin Pediatr Dent 2018; 11(5):382-5. https://doi.org/10.5005/jp-journals-10005-1544

[12] Palti DG, Machado MA, Silva SM, Abdo RC, Lima JE. Evaluation of superficial microhardness in dental enamel with different eruptive ages. Braz Oral Res 2008; 22(4):31 1-5. https://doi.org/10.1590/s 1806-83242008000400005

[13] Sawusch RH. Pulpal management of permanent first molars with open apices: case history. Pediatr Dent 1983; $5(1): 30-2$ 
[14] Do LG, Spencer A. Oral health-related quality of life of children by dental caries and fluorosis experience. J Public Health Dent 2007; 67(3):132-9. https://doi.org/10.1111/j.1752-7325.2007.00036.x

[15] Fejerskov O. Changing paradigms in concepts on dental caries: consequences for oral health care. Caries Res 2004; 38(3):182-91. https://doi.org/10.1159/000077753

[16] O'Leary TJ, Drake RB, Naylor JE. The plaque control record. J Periodontol 1972; 43(1):38. https://doi.org/10.1902/jop.1972.43.1.38

[17] Mahboobi Z, Pakdaman A, Yazdani R, Azadbakht L, Shamshiri AR, Babaei A. Caries incidence of the first permanent molars according to the Caries Assessment Spectrum and Treatment (CAST) index and its determinants in children: a cohort study. BMC Oral Health 2021; 21(1):259. https://doi.org/10.1186/s12903-021-01612-1

[18] Gudipaneni RK, Alkuwaykibi AS, Patil SR, Assiry A, Alam MK, Vundavalli S. Assessment of caries spectrum of first permanent molars in 7-to 8-year-old school children in Northern Saudi Arabia: a cross-sectional study. Pesqui Bras Odontopediatria Clín Integr 2020; 20:e4800. https://doi.org/10.1590/pboci.2020.005

[19] Frazao P. Epidemiology of dental caries: when structure and context matter. Braz Oral Res 2012; 26(Suppl 1):108-14. https://doi.org/10.1590/s1806-83242012000700016

[20] Ekstrand KR, Christiansen J, Christiansen ME. Time and duration of eruption of first and second permanent molars: a longitudinal investigation. Community Dent Oral Epidemiol 2003; 31(5):344-50. https://doi.org/10.1034/j.1600-0528.2003.00016.x

[21] Souza RA, Gomes SCN, Dantas JCP, Silva-Sousa YT, Pecora JD. Importance of the diagnosis in the pulpotomy of immature permanent teeth. Braz Dent J 2007; 18(3):244-7. https://doi.org/10.1590/s0 103-64402007000300013

[22] Guerrero F, Mendoza A, Ribas D, Aspiazu K. Apexification: A systematic review. J Conserv Dent 2018; $21(5): 462-5$. https://doi.org/10.4103/JCD.JCD_96_18

[23] Nicoloso GF, Goldenfum GM, Pizzol TDSD, Scarparo RK, Montagner F, de Almeida Rodrigues J, Casagrande L. Pulp revascularization or apexification for the treatment of immature necrotic permanent teeth: systematic review and meta-analysis. J Clin Pediatr Dent 2019; 43(5):305-13. https://doi.org/10.17796/1053-4625-43.5.1

[24] Maltz M, Jardim JJ, Alves LS. Health promotion and dental caries. Braz Oral Res 2010; 24(Suppl 1):18-25. https://doi.org/10.1590/s1806-83242010000500004

[25] Twetman S. Caries risk assessment in children: how accurate are we?. Eur Arch Paediatr Dent 2016; 17(1):27-32. https://doi.org/10.1007/s40368-015-0195-7

[26] Moreira KMS, Vargas AMD, Normando D, Ferreira EF. Plaque control on the permanent first molar: cost/benefit analysis. Arq Odontol 2016; 52(2):64-69.

[27] Roncalli AG. National oral health survey in 2010 shows a major decrease in dental caries in Brazil. Cad Saude Publica 2011; 27(1):4-5. https://doi.org/10.1590/s0102-311x2011000100001

[28] Quaglio JM, Sousa MB, Ardenghi TM, Mendes FM, Imparato JC, Pinheiro SL. Association between clinical parameters and the presence of active caries lesions in first permanent molars. Braz Oral Res 2006; 20(4):358-63. https://doi.org/10.1590/s1806-83242006000400014

[29] Silva AJ, Santos LCL, Sá JMA, Andrade BRB, Ponzi EAC, Barreira AK. Loss of permanent first molars in children and adolescents attended at the Clínica-Escola de Odontologia - UFPE. Elect J Collec Health 2019; 11(17):1-9.

[30] Artun J, Thalib L. Mesial migration and loss of first molars among young adolescents in Kuwait. Community Dent Health $2011 ; 28(2): 154-9$

[31] Alkhadra T. A systematic review of the consequences of early extraction of first permanent first molar in different mixed dentition stages. J Int Soc Prev Community Dent 2017; 7(5):223-6. https://doi.org/10.4103/jispcd.JISPCD_222_17 